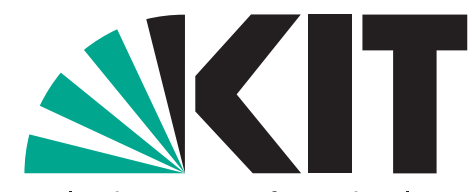

Karlsruher Institut für Technologie

\title{
Green attitude and economic growth
}

by Ingrid Ott and Susanne Soretz

No. 68 | MAY 2015

\section{WORKING PAPER SERIES IN ECONOMICS}

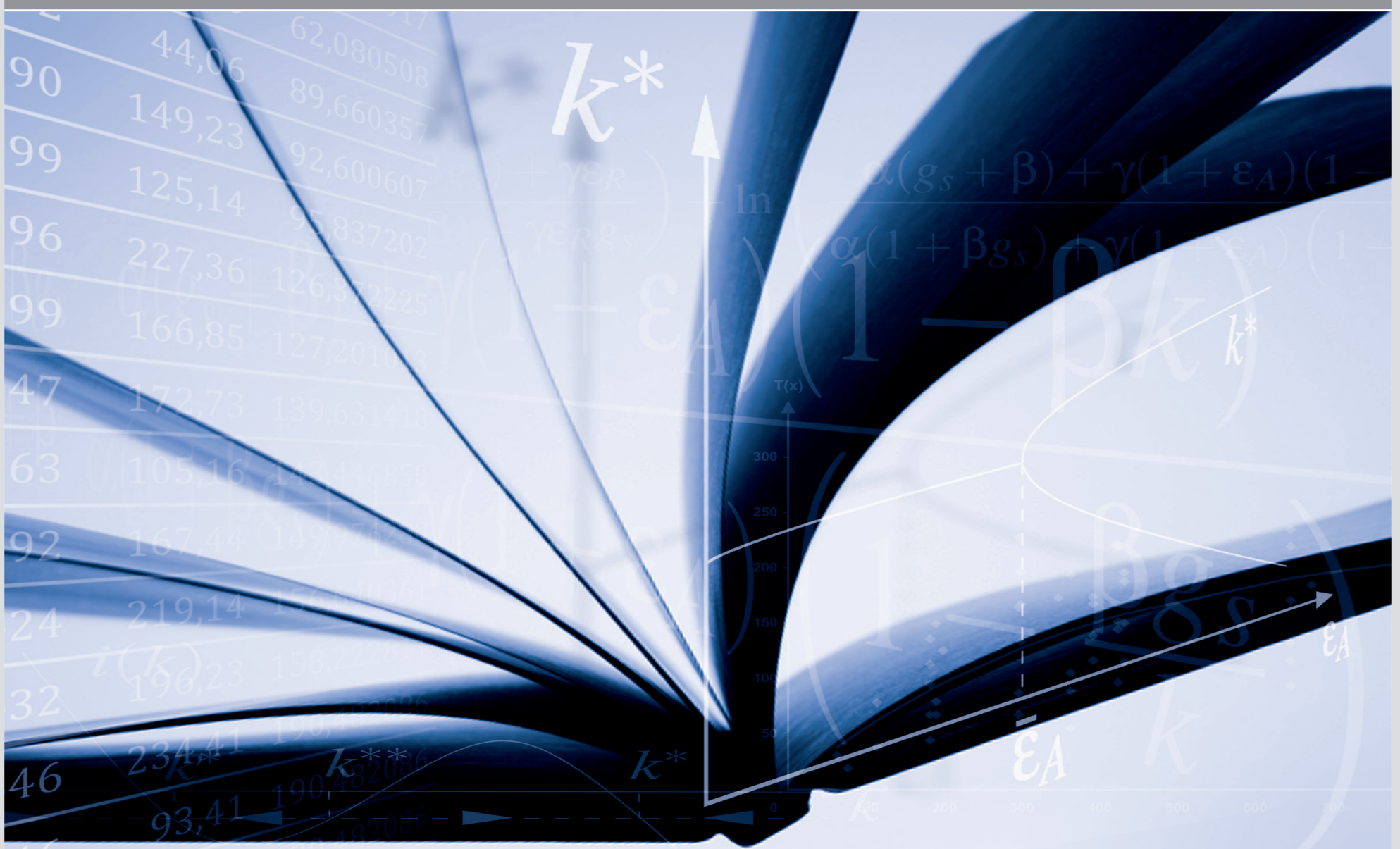




\section{Impressum}

Karlsruher Institut für Technologie (KIT)

Fakultät für Wirtschaftswissenschaften

Institut für Volkswirtschaftslehre (ECON)

Schlossbezirk 12

76131 Karlsruhe

KIT - Universität des Landes Baden-Württemberg und nationales Forschungszentrum in der Helmholtz-Gemeinschaft

Working Paper Series in Economics

No. 68, May 2015

ISSN 2190-9806

econpapers.wiwi.kit.edu 


\title{
Green attitude and economic growth
}

\author{
Ingrid Ott* und Susanne Soretz**
}

May 8, 2015

\begin{abstract}
We analyse the interdependence between green attitude and equilibrium development of environmental quality in an endogenous growth model. Individuals take only part of their impact on pollution into account, hence there is a negative externality of capital accumulation on environmental quality. Increasing wealth or increasing pollution enhance green attitude and reduce the externality, because individuals care more about the environment if their income is higher or if pollution is more obvious. The time path of pollution as well as the evolution of equilibrium growth are shown to depend crucially on the determinants of green attitude. If green attitude improves with increasing wealth, e.g. as a consequence of an increase in environmental education, the economy converges to the sustainable growth path and in the long run, also the optimal level of environmental quality is realized. In contrast, pollution remains at a suboptimally high level if individual attitude towards the environment is influenced by pollution itself, that means, if individuals care the more about environmental issues the worse environmental quality.
\end{abstract}

JEL-Classification: O1, O4, Q2, Q5

Keywords: pollution, endogenous growth, green attitude.

${ }^{*}$ Karlsruhe Institute of Technology and Kiel Institute for the World Economy, e-mail: ingrid.ott@kit.edu

**Universität Greifswald, e-mail: soretz@uni-greifswald.de 


\section{Introduction}

Recent research in various disciplines identifies an increased sensitivity of individuals as regards environmental problems such as pollution, loss of biodiversity, global warming, ozone depletion or tropical deforestation. Summarizing this, the European Commission (2008, p. 3) states within the Special Eurobarometer 295 entitled 'Attitudes of European Citizens towards the Environment' that: "...citizens are becoming more aware of both the potential effects of these problems in their daily lives and the role they could play in protecting their environment." Follow-up studies confirm these preoccupations (see e. g. European Commission 2011).

In industrialized economies, individual awareness of environmental issues strengthens over time, e. g. by increasing pollution, environmental education or increasing income. Hence, perception of environmental degradation is endogenous and as a consequence, pollution and accumulation dynamics become considerably more complex. Therefore we focus on the determinants of environmental externalities as well as on their evolution on the growth path. We show that the properties of dynamic market equilibrium depend crucially on whether and in which way individual attitude towards the environment is influenced by economic development. The relevance of pollution perception for the resulting time path of environmental quality was also discussed by Schumacher and Zou (2008) who show that pollution perception may change the dynamics qualitatively and lead to intergenerational inequity.

In order to analyse these arguments, we ascribe the environmental externality to partial perception of the individual impact on environmental quality corresponding to partial rivalry in congestion models, see Glomm and Ravikumar (1994), Fisher and Turnovsky (1998) or Eicher and Turnovsky (2000). Individuals recognize environmental quality to be influenced in part by themselves and in part by the rest of the society. Consequently, they only feel partially responsible for the level of pollution, and this partial responsibility may increase in the process of economic growth. European citizens e. g. are shown to undertake more environmentally-friendly actions if they are highly educated and well-informed about the environment (see European Commission 2011, p. 29). Another example is the rapidly increasing demand for organic products in most industrialized countries.

We distinguish two possible impacts of economic development on green attitude. First, wealth is an important determinant of individual attitude towards the environment. Richer nations can spend more on environmental education, richer individuals are able to spend more for green consumption. Hence green attitude will strengthen with an increase in wealth. The second determinant we regard is pollution itself. As environmental quality decreases, individuals will be more concerned with environmental issues and hence care 
more about the environment. For example, directly after the Fukushima nuclear accident a great majority emerged in favour of a switch to green energy, combined with a noticeable increase in the willingness to pay.

We analyse the interdependence between green attitude and economic and environmental development. The individual attitude towards the environment determines the extent of the negative externality and therefore accumulation and abatement decisions. Capital accumulation and environmental quality in turn determine the evolution of green attitude. The resulting dynamics are complex. Pollution level and growth rate may decrease monotonically during the growth process and eventually converge to their optimal levels. But depending on the characteristics of green attitude adjustment and on the specific level of environmental quality, capital growth may even result suboptimally low in the transition process, combined with still suboptimally high pollution. The outcome depends predominantly on the nature of the influence of increasing wealth and environmental quality on the evolution of green attitude.

Externalities associated with environmental goods are well-known to cause suboptimally high economic growth in dynamic market equilibrium, at least if pollution is a by-product of the consumption good. Brock and Taylor (2005) or Xepapadeas (2005) provide comprehensive overviews. There is a wide literature on environmental policy in endogenous growth models, see Stokey (1998) with a focus on tax and voucher schemes, or Grimaud (1999) and Ono (2002) both analysing pollution permits. More recently, there was a shift of emphasis on human capital and R\&D: Grimaud and Tournemaine (2007) as well as Pautrel (2012) work on the growth impact of environmental policy in corresponding endogenous growth settings. Our focus is different. We show that endogenization of environmental externalities changes important features of dynamic market equilibrium, which in turn have do be regarded in order to evaluate environmental policy measures correctly.

After the presentation of the assumptions in Section 2 we analyse the dynamic equilibrium in Section 3. Section 4 discusses the endogenous determination of green attitude. If green attitude gains importance throughout the growth process due to increasing wealth (section 4.1), the equilibrium growth path converges to the sustainable growth path. If instead increasing pollution is the determinant for individual perception of environmental quality (section 4.2), we show that the steady state pollution level as well as steady state growth remain suboptimally high. Section 4.3 explains the complex dynamic structure when both increasing wealth and pollution jointly determine green attitude. Section 5 concludes. 


\section{The model}

\subsection{Environmental quality and green attitude}

There is evidence that the extent of environmental externalities and free rider behaviour changes in time. For example, all but $5 \%$ of European citizens consider the protection of the environment as important to them personally (European Commission 2011, question QB1), as displayed in figure 1(a). Furthermore, a great majority of Europeans think that the citizens themselves are not doing enough for environmental quality, see figure 1(b). A usual outcome concerning externalities is that $79 \%$ of the respondents think that corporations and industry should do more to protect the environment. Correspondingly, $72 \%$ (63\%) answer that the national governments (the European Union) don't do enough to use natural resources efficiently. But astonishingly, $69 \%$ of the informants feel that the individuals themselves should behave more environmentally friendly.

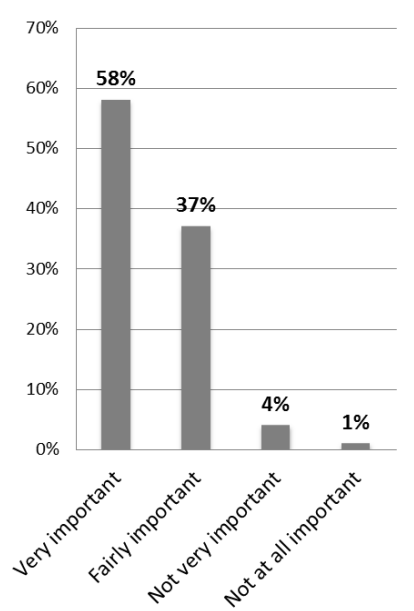

(a) "How important is protecting the environment to you personally?"; question QB1



(b) "In your opinion, are each of the following currently ... doing too much, ... doing about the right amount, or ... not doing enough to use natural resources efficiently?"; question QB17

Figure 1: Green attitude; based on questions in Special Eurobarometer 365, European Commission (2011)

We consider the growth path of an economy in which environmental pollution results from production of the homogenous consumption good. Environmental damage increases jointly with an increasing capital stock, $K$, and decreases with abatement activity, $E .{ }^{1}$ More concretely, pollution emerges according to $K(t) / E(t)$. This presentation is based, among

\footnotetext{
${ }^{1}$ Due to linear production technology as given in equation (5), the interdependency between pollution and capital stock is equivalent to pollution out of production.
} 
others, on Smulders and Gradus (1996) who show within a more general approach that a sustainable growth path (as represented by a non-increasing level of pollution together with non-decreasing per-capita income, see e. g. ?, p. 147) may only be achieved if the pollution elasticity of capital does not exceed the pollution elasticity of environmental expenditure. We apply this result by assuming identical elasticity that (without a loss of generality) equals unity.

Green attitude is captured by the parameter $\delta$ which indicates that individuals perceive their influence on pollution only partially. In other words, the individuals do not realize the entire impact of their economic activity on the resulting pollution level. A related approach to pollution perception can be found in Schumacher and Zou (2008). The partial perception induces an external effect which ends up in a suboptimally high equilibrium level of pollution. Environmental pollution is perceived by the individuals according to the function

$$
P(t)=\left(\frac{K(t)}{E(t)}\right)^{\delta}\left(\frac{k(t)}{e(t)}\right)^{1-\delta}, \quad 0 \leq \delta<1
$$

where $K$ and $E$ denote the aggregate levels of capital and expenditure for environmental protection; $k$ and $e$ are the respective individual variables. Assuming homogeneity of individuals, the aggregate ratio $K / E$ and the individual ratio $k / e$ coincide, hence in equilibrium perceived pollution equals actual pollution $P(t)=K(t) / E(t)$. With this respect our approach to pollution perception differs from the one of Schumacher and Zou (2008). In our model, individuals are affected by actual pollution. But within utility maximization they calculate their impact on pollution as given by pollution perception (1).

The parameter $\delta$ denotes the share of pollution that is perceived as being exogenous to the individual's decision. Thus, $\delta=0$ reflects the absence of any externality, i. e. the individuals perceive the entire (negative) impact of their actions on the resulting pollution level correctly. If, in contrast, $\delta$ is close to unity, the individuals perceive their own impact as atomistic and thus negligible. Thus, an environmental externality arises whenever $\delta$ is positive. Then the influence of individual decisions on environmental quality is underestimated. $^{2}{ }^{3}$ An improvement of green attitude hence corresponds to a decline in $\delta$.

In reality, individuals show free rider behaviour, but they don't exclusively free ride. To

\footnotetext{
${ }^{2}$ A related argumentation can be found in Eriksson (2004) who argues that individual preferences for environmentally friendly goods lead to a partial internalization of externalities.

${ }^{3}$ Alternatively one might interpret $1-\delta$ as degree of rivalry for environmental pollution. This is analogue to the presentation of congestion effects in the context of public goods (compare e.g. Edwards 1990, Glomm and Ravikumar 1994, Turnovsky 2000, chap. 13). Most environmental goods are characterized by partial rivalry, i.e. they are described by $1>\delta>0$. Organic food, e.g., reduces individual pollution loads. This represents a kind of consumption rivalry. At the same time, the production of organic food also reduces pollution loads of the entire cultivable land. This benefits the other producers equally, i.e. there is no rivalry.
} 
some extent they act environmentally friendly. There are several actions the European citizens execute due to environmental reasons, see figure 2. First of all, individuals separate waste (around $60 \%$ of respondents). But they also cut down their energy consumption (around 50\%) and they even use their car less (around 20\%) in order to contribute to the improvement of environmental quality. In the terminology of our assumptions, this means that the perception parameter $\delta$ indeed is below unity. Moreover, the number of European citizens who act environmentally friendly in order to help towards less pollution increases in time, as impressively shown in figure 2 . Again transferred into our model, this means that green attitude improves and the perception parameter $\delta$ decreases in time.



Figure 2: "Have you done any of the following during the past month for environmental reasons?"; question QB12, European Commission (2011)

Important determinants of the evolution of green attitude are education and income. Within the Special Eurobarometer, respondents were asked "As an individual, you can play a role in protecting the environment in your country?". Individuals estimate their influence on environmental protection the higher the more educated they are and the higher their personal income (see European Commission 2011, question QB 14.1, p. 20). With longer education time individuals know more about the impact of economic decisions on environmental quality. With increasing aggregate income usually the average education level enhances, and with increasing individual income people are able to behave more environmentally friendly. Moreover, people with higher income are more concerned with environmental problems, as e. g. described by Glaeser (2005). Glaeser emphasizes that the correlation between GDP and "... viewing global warming as a [personal] threat ... 
could also be explained by a more robust market for ideas in wealthier countries, in that their citizens feel free to express thoughts and debate issues without fear of repercussions from the government" (see Glaeser 2005, p. 210).

Another essential factor of individual environmental perception is environmental quality on its own. As long as the pollution level is low, individuals do not care about the impact of their actions on environmental quality but only consider their impact on the resulting consumption path. As pollution increases, the negative impact of capital accumulation on environmental quality becomes visible and thus fosters environmental awareness of the individuals. For example, the survey underlying the Eurobarometer 365, (European Commission 2011) was carried out in april and may 2011, in direct succession of the Gulf of Mexico oil spill and the Fukushima nuclear accident. As a consequence, man-made disasters followed by water pollution were mentioned most freqently in 2011 to provoke the biggest effects of environmental change (see European Commission (2011, p. 14)). As also described by Schumacher (2009) green attitude will be the more likely if the pollution level is high. The environmental consequences of economic decisions are more obvious, hence green attitude will enhance.

In what follows we assume that green attitude is determined by economic development as well as by the pollution level. The perceived impact of individual activity on environmental pollution is positively linked to increasing wealth, $k$. For less developed economies, the perception parameter $\delta$ is high and decreases throughout the growth process. This is a shortcut for the effort in environmental education, the possibilities for green consumption, larger freedom of expression and so on. Second, green attitude is positively linked to increasing pollution, $P$. Given low pollution levels, $P$, the perception parameter $\delta$ will be high and decreases with a rise in pollution. Formally spoken, we assume

$$
\begin{aligned}
\delta=\delta(k, P) \quad \text { with } \quad & \delta_{k}<0, \delta_{k k}>0, \quad \delta_{P}<0, \delta_{P P}>0 \\
& \delta\left(k_{0}, P_{0}\right)<1, \lim _{k \rightarrow \infty} \delta=0, \lim _{P \rightarrow \infty} \delta=0
\end{aligned}
$$

\subsection{Further assumptions}

Environmental pollution affects individual decisions as it induces dis-utility. We assume a continuum of infinitely lived individuals who maximize intertemporal utility. Intertemporal utility, however, might also be interpreted in a model of overlapping generations where parents are altruistic with respect to their own children - an assumption that is especially plausible in the context of environmental quality which frequently only becomes prevalent for subsequent generations. 


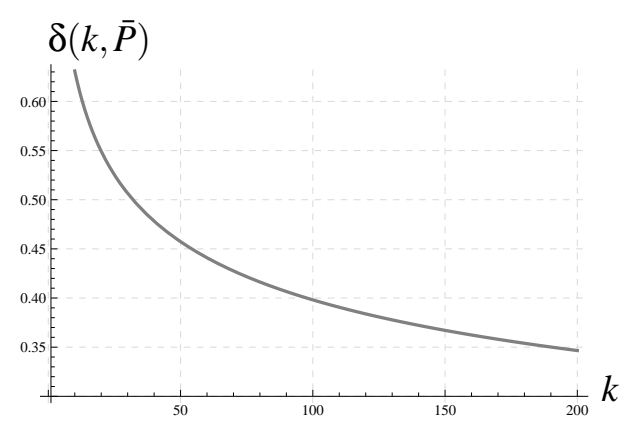

(a) Green attitude determined by wealth, $\delta(k, \bar{P})$

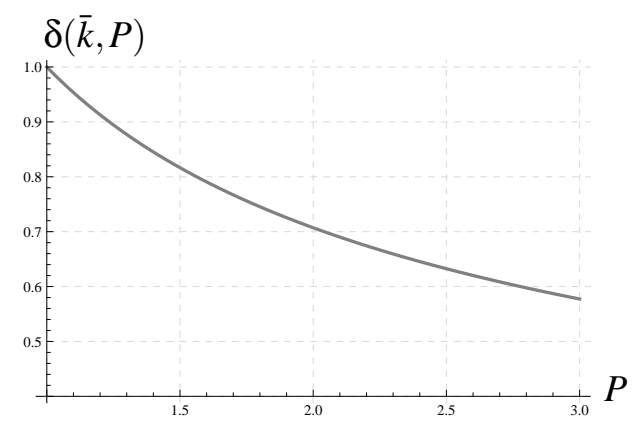

(b) Green attitude determined by pollution, $\delta(\bar{k}, P)$

Figure 3: Evolution of green attitude

Intertemporal utility is assumed to be additively separable across time and is given by

$$
U=\int_{0}^{\infty} \exp (-\rho t) u(c, P) d t
$$

The parameter $\rho>0$ denotes the rate of time preference. Especially in the context of sustainability, the choice of a positive rate of time preferences has been critically discussed already by Ramsey (1928, p. 543) who stated that discounting future utility reflects "... a practise which is ethically indefensible and arises merely from the weakness of the imagination." The assumption of a positive rate of time preference, however, within this paper is chosen since we intend to describe the real development of an economy and not a socially desired time path. The assumption of a positive discount rate is also supported by empirical studies that show that the real rate of return on capital exceeds the growth rate of an economy significantly.

Instantaneous utility, $u(c, P)$, is characterized by a constant intertemporal elasticity of substitution, $\varepsilon$, as well by an intratemporal elasticity of substitution between consumption and pollution equal to unity. Notice that both are knife-edge assumptions which reflect necessary preconditions for the existences of a sustainable growth path with a constant level of pollution (compare e.g. Smulders and Gradus 1996). Thus the intratemporal utility function is given by

$$
u(c, P)=\frac{\left(c P^{-\gamma}\right)^{1-1 / \varepsilon}}{1-1 / \varepsilon}, \quad 0<\varepsilon<1, \quad \gamma>0 .
$$

The additional assumption that the intertemporal elasticity of substitution has to fall short of unity results from unequivocal empirical studies (e.g. Hall 1988, Epstein and Zin 1989). The parameter $\gamma$ represents the relative impact of dis-utility out of environmental pollution.

The linear production of the homogenous consumption good is given by

$$
f(k)=A k, \quad A>0 .
$$


The only productive input is capital that shall be broadly interpreted to include, e.g. human capital. In order to focus on environmental externalities, we abstract from further externalities within consumption good production.

\section{Equilibrium growth and environmental quality}

\subsection{Dynamic optimization}

In the following we analyse the dynamic market equilibrium and focus on the implications of green attitude. The resulting growth rate is unequivocally smaller than in an economy without pollution, i.e. with clean technology. ${ }^{4}$ Besides, it is shown that the equilibrium environmental quality is the lower, the lower is the extent of environmental pollution that individuals perceive as being the outcome of their own activity. Nevertheless, the dynamics resulting from the interdependence between capital accumulation, green attitude and pollution result to be more complex.

To determine the growth equilibrium the individual maximizes intertemporal utility subject to private capital accumulation

$$
\begin{array}{ll}
\max _{c, e, k} & U=\int_{0}^{\infty} \exp (-\rho t) u(c, P) d t \\
\text { s. t. } & \dot{k}=A k-c-e
\end{array}
$$

The individual decides on consumption, $c$, abatement activity, $e$, and on capital accumulation, $k$. Pollution is perceived according to assumption (1) and green attitude evolves as assumed in (2). The resulting first-order conditions are thus

$$
\begin{aligned}
& \frac{\partial \mathcal{H}}{\partial c}=\exp (-\rho t) u_{c}-\lambda \stackrel{!}{=} 0 \\
& \frac{\partial \mathcal{H}}{\partial e}=-\exp (-\rho t) u_{P}\left(1-\delta+\delta_{P} P\left(\ln \left(\frac{K}{E}\right)-\ln \left(\frac{k}{e}\right)\right)\right) \frac{P}{e}-\lambda \stackrel{!}{=} 0 \\
& \frac{\partial \mathcal{H}}{\partial k}=\exp (-\rho t) u_{P}\left(1-\delta+k \delta_{k}\left(\ln \left(\frac{K}{E}\right)-\ln \left(\frac{k}{e}\right)\right)\right) \frac{P}{k}+\lambda A \stackrel{!}{=}-\dot{\lambda}
\end{aligned}
$$

Equalizing (7) and (8) together with the equilibrium feature $K / E=k / e$ leads to the (individually) optimal allocation of consumption and environmental expenditure

$$
\frac{e}{c}=\gamma(1-\delta)
$$

\footnotetext{
${ }^{4}$ This result is closely related to the assumption of a one-sector economy. If there were, e.g. an additional sector for human capital that accumulates without pollution, pollution had neither impact on the optimal nor on the equilibrium growth rate (e.g. Gradus and Smulders 1993)
} 
The ratio between expenditures in environmental protection, $e$, and consumption, $c$ is determined by the environmental preferences, $\gamma$, and attitude towards the environment, $\delta$. The higher the perceived dis-utility out of pollution, the higher are relative abatement expenditures. This already points up to the central impact of individual perception of environmental quality: The higher the share $\delta$ of environmental quality, which seems to be the outcome of the aggregate (and thus not being a result of individual behaviour), the lower is the individually perceived utility out of environmental expenditure and thus the lower is the corresponding budget invested in environmental protection.

Utilizing $\dot{\lambda}$ derived from (7) together with (9) provides the Keynes-Ramsey rule which describes the growth rate of consumption

$$
\hat{c}=\varepsilon\left(A-\gamma(1-\delta) \frac{c}{k}-\rho-\gamma(1-1 / \varepsilon) \hat{P}\right)
$$

Private capital return $A$ is reduced by environmental damage, indicated by abatement activity $\gamma(1-\delta) c / k$. Along the equilibrium growth path, the abatement ratio, $e / k$, and thus the growth rate of pollution, $\hat{P}=-\widehat{e / k}$, are endogenously determined.

Concerning the evolution of environmental quality, one has to bear in mind that following (10) abatement activity on the one hand increases with expenditure for consumption goods (both consumption and environmental quality are complementary arguments within the utility function (4)). On the other hand abatement also increases within the growth process due to stronger attitude towards the environment.

$$
\hat{P}=\hat{k}-\hat{e}=\hat{k}-\widehat{(1-\delta)}-\hat{c}
$$

Since green attitude, $\delta$, evolves depending on wealth, $k$, and environmental quality, $P$, definition of the elasticities $\xi_{k}=\delta_{k} k / \delta$ and $\xi_{P}=\delta_{P} P / \delta$ allows the representation

$$
\widehat{(1-\delta)}=-\frac{\delta}{1-\delta} \hat{\delta}=-\frac{\delta}{1-\delta}\left(\xi_{k} \hat{k}+\xi_{P} \hat{P}\right)
$$

Note that both elasticities, $\xi_{k}$ and $\xi_{P}$, are negative. Hence, if capital or pollution increase, $(1-\delta)$ will rise, too. This mirrors our assumptions about green attitude: increasing wealth allows for more environmental education, or more pollution increases environmental awareness, both reducing the part $\delta$ of pollution which seems to be unrelated with individual economic decisions.

As given in the appendix, capital growth results in

$$
\hat{k}(\delta(k, P))=\hat{c}(\delta(k, P))=\frac{\varepsilon(A-(1+\gamma(1-\delta)) \rho)}{1+(1-\varepsilon) \gamma\left(1-\delta-\frac{\delta \xi_{k}(1+\gamma(1-\delta))}{1-\delta-\delta \xi_{P}}\right)}
$$


and the time path of pollution follows

$$
P(\delta(k, P))=\frac{1+(1-\varepsilon) \gamma\left(1-\delta-\frac{\delta \xi_{k}(1+\gamma(1-\delta))}{1-\delta-\delta \xi_{P}}\right)}{(1+\gamma(1-\delta))\left(\varepsilon \rho+(1-\varepsilon)\left(1-\frac{\gamma \delta \xi_{k}}{1-\delta-\delta \xi_{P}}\right) A\right)}
$$

Economic growth and environmental quality hence are dynamically interdependent. In order to disentangle the various occurring effects, first we analyse the case of exogenous and constant attitude towards the environment as a reference situation. Subsequently we show that the impact of wealth on green attitude reduces capital growth and induces an adjustment towards the sustainable pollution level. Afterwards we focus on the impact of pollution on green attitude which can be shown to hamper the adjustment towards the optimal growth path.

\subsection{Exogenous attitude towards the environment}

If individual attitude towards the environment is exogenously given and constant, $\delta=\bar{\delta}$, the economy will immediately realise steady state growth. It can easily be seen from equation (10) that with invariant attitude towards the environment (hence $\bar{\delta}_{k}=\bar{\delta}_{P}=0$ ) the equilibrium growth path implies that environmental expenditures and consumption grow at the same and constant rate. ${ }^{5}$ In this case, the macroeconomic variables all grow at the same rate thereby leading to constant levels of abatement ratio, $e / k$, and pollution, $P$. The growth rate then just differs from the one in an economy which produces without pollution, $\varepsilon(A-\rho)$, by the term $-e / k$, or put differently, equilibrium growth is unequivocally smaller if pollution arises: pollution which is linked to capital accumulation reduces the effective marginal product of capital and thus the economy's equilibrium growth rate.

Combining abatement activity (10), consumption growth (11) and capital growth (A.2) allows for the explicit determination of the growth rate and the pollution level

$$
\begin{aligned}
\hat{k}(\overline{\boldsymbol{\delta}}) & =\hat{c}(\overline{\boldsymbol{\delta}})=\frac{\varepsilon(A-(1+\gamma(1-\bar{\delta}) \rho))}{1+(1-\varepsilon) \gamma(1-\bar{\delta})} \\
P(\bar{\delta}) & =\frac{1+(1-\varepsilon) \gamma(1-\bar{\delta})}{\gamma(1-\bar{\delta})(\varepsilon \rho+(1-\varepsilon) A)}
\end{aligned}
$$

The more pronounced environmental preferences (i.e. higher $\gamma$ ) the lower is the equilibrium growth rate. Pollution induces a dis-utility which reduces capital productivity and thus also private capital accumulation. This effect is magnified if the perception parameter, $\bar{\delta}$, decreases which implies that a bigger part of pollution is ascribed to individual decisions. The impact of perceived pollution on individual accumulation is captured within

\footnotetext{
${ }^{5}$ This is the result of the intratemporal elasticity of substitution which equals unity, as already shown in Smulders and Gradus (1996).
} 
the term $\gamma(1-\bar{\delta})$. Incomplete perception of the impact of individual decisions on the pollution level, i.e. $\bar{\delta}>0$, results in a suboptimally high growth rate. Part of the negative effect of capital accumulation via pollution on intertemporal utility is neglected which leads to an overestimation of capital productivity. Consequently equilibrium growth is suboptimally high. Complete knowledge about the relationships between individual and aggregate dimensions as regards the evolution of pollution $(K / E=k / e$ and thus $P=k / e$ which is equivalent to the polar case $\delta=0$ ) would result in optimal growth and optimal pollution level

$$
\begin{aligned}
& \hat{k}^{*}=\hat{c}^{*}=\frac{\varepsilon(A-(1+\gamma) \rho)}{1+(1-\varepsilon) \gamma} \\
& P^{*}=\frac{1+(1-\varepsilon) \gamma}{\gamma(\varepsilon \rho+(1-\varepsilon) A)}
\end{aligned}
$$

As expected equilibrium growth (16) exceeds optimal growth (18) and equilibrium pollution (17) exceeds optimal pollution (19) confirming the well-known impact of a negative externality in capital accumulation on the growth rate in market equilibrium.

Indeed, environmental preferences and the attitude towards the environment jointly influence the effective intertemporal elasticity of substitution as well as the effective rate of time preference. The effective intertemporal elasticity of substitution, $\varepsilon /(1+(1-\varepsilon) \gamma(1-$ $\bar{\delta})$ ), is lower than $\varepsilon$ due to environmental preferences $(\gamma>0)$ and due to environmental awareness $(\bar{\delta}<1)$. The lower the effective intertemporal elasticity of substitution, the lower is the growth rate for any given private capital return, $A$. Additionally, the effective rate of time preference, $(1+\gamma(1-\bar{\delta})) /(1+(1-\varepsilon) \gamma(1-\bar{\delta}))$, is higher than $\rho$ due to pollution and the awareness of pollution. This reinforces the growth diminishing impact described just before.

The suboptimally low level of pollution in dynamic equilibrium could motivate to internalize the pollution externality via a sophisticated tax-transfer-system. Within the provided framework this could be done e. g. via the implementation of a tax on pollution or capital returns respectively together with a subsidy on environmental protection. Since in the underlying model the environmental policy measures work in the well-known way we forgo their analysis here.

However, at the same time this raises the question about the determinants of green attitude and it is quite implausible to assume that this characteristic remains constant as an economy evolves. We will now come back to the assumption that green attitude is determined by wealth and by pollution as given in (2). Hence dynamics will be more complex. Equation (10) already shows that with endogenous attitude towards the environment the growth rates of abatement, $e$, and consumption, $c$, will differ. When green attitude gains importance, $(1-\delta)$ increases and environmental expenditures grow faster than consumption. Hence, the economy cannot realise steady state immediately. 
The following part analyses the impact of endogenous environmental attitude on aggregate growth and the evolution of the pollution level. In doing so, we explicitly focus on two different initial points: We begin with a situation in which environmental perception is solely linked to increased welfare (section 4.1). In section 4.2 we focus on the impact of pollution on green attitude. Then we combine the arguments in section 4.3.

\section{Endogenous green attitute}

\subsection{Green attitude determined by wealth}

In what follows we assume that the individual attitude towards the environment may be explained by the economic development, i.e. the perceived impact of individual activity on environmental pollution is positively linked to increasing wealth, $k$. Concerning the perception function $\delta(k)$ we assume $\delta_{k}<0$ and $\delta_{k k}>0$, with $\delta\left(k_{0}\right)<1$ and $\lim _{k \rightarrow \infty} \delta=0$ (as given in Figure 3(a)). Furthermore, we abstract from any impact of pollution on environmental awareness, that is $\delta_{P}=\xi_{P}=0$.

The evolution of the macroeconomic variables throughout the process of convergence to the long-run equilibrium may be derived from equations (14) and (15) by setting $\xi_{P}=$ 0 . Along the equilibrium transition path, the individuals again will choose a constant consumption ratio. This implies that capital and consumption grow at the same rate. Environmental expenditure then follow

$$
\hat{e}=\widehat{(1-\delta)}+\hat{k}
$$

Since with increasing wealth also a bigger share of pollution is attributed to own individual decisions (i.e. decreasing $\delta$ ), environmental awareness and thus the perceived impact of ongoing capital accumulation on pollution increases. Consequently, the growth rate of abatement activity exceeds the growth rate of private capital and environmental quality evolves according to $\hat{P}=\xi_{k} \frac{\delta}{1-\delta} \hat{k}<0$. A growing economy will thus always be characterized by a decreasing pollution level since stronger attitude towards the environment (due to $\left.\xi_{k}<0\right)$ makes abatement grow faster than the capital stock.

Within the transition process, capital growth and pollution level result in

$$
\begin{gathered}
\hat{k}(\delta(k))=\frac{\varepsilon(A-\rho(1+\gamma(1-\delta)))}{1+(1-\varepsilon) \gamma(1-\delta \underbrace{\delta-\frac{\delta}{1-\delta} \xi_{k}(1+\gamma(1-\delta))}_{+})} \\
P(\delta(k))=\frac{1+(1-\varepsilon) \gamma\left(1-\delta-\frac{\delta \xi_{k}(1+\gamma(1-\delta))}{1-\delta-\delta \xi_{P}}\right)}{(1+\gamma(1-\delta))\left(\varepsilon \rho+(1-\varepsilon)\left(1-\frac{\gamma \delta \xi_{k}}{1-\delta-\delta \xi_{P}}\right) A\right)}
\end{gathered}
$$


Compared with capital growth in case of exogenous attitude (16), the effective intertemporal elasticity of substitution is decreased due to the evolution of green attitude. The denominator in (21) is larger than in (16), hence equilibrium growth is smaller if increasing wealth strengthens the attitude for the environment. The reason is that abatement activity increases when individuals' attitude becomes greener. The increase in the abatement ratio decreases effective capital return as can be seen in the Keynes-Ramsey-rule (11). The resulting growth effect is twofold: First, as $\delta$ decreases, the growth rate of capital decreases. Additionally, as $\delta$ will go on to decrease in all future time increments, capital accumulation is further reduced. This second argument is displayed by the positive term marked in the growth rate (21).

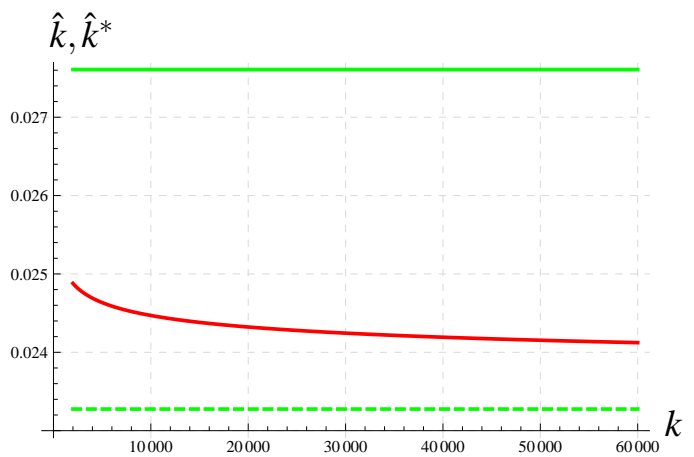

(a) small impact of wealth: $\xi_{k}=-0.2$

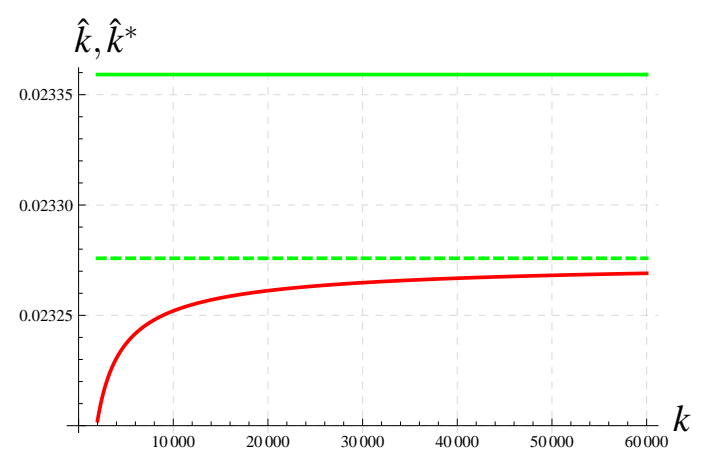

(b) large impact of wealth: $\xi_{k}=-0.7$

Figure 4: Transitional dynamics: evolution of the growth rate; solid red line: $\hat{k}(\delta(k))$ from (21), dashed green line: $\hat{k}^{*}$ from (18), solid green line: $\hat{k}(\bar{\delta})$ from (16); parameters: $\varepsilon=0.05, \rho=0.05, A=1.5, \gamma=2$

Figure 4 displays the evolution of capital growth. First, capital growth is unambiguously reduced if green attitude is fostered by capital accumulation. During the growth process green attitude evolves, hence the parameter $\delta$ decreases and the negative environmental externality diminishes. Capital growth decreases in time, as abatement activity increases, this case is shown in figure 4(a). Nevertheless, figure 4(b) shows that the growth reduction induced by the impact of wealth on green attitude may even overcompensate the negative externality with respect to capital accumulation. During the transition process, capital growth may result suboptimally low, if wealth has a large impact on green attitude. The growth reduction implied by the continuous decrease in future capital return due to the perpetually enhancing green attitude is larger than the overaccumulation implied by the environmental externality. However, the more realistic parameter setting is an only small impact of wealth on green attitude, corresponding to figure 4(a).

Independent from the magnitude of the impact of wealth on green attitude, the pollution level is suboptimally high in the transition process. This is a direct consequence of the negative environmental externality. As long as individuals neglect part of the influence of 
their decisions on pollution (that means $\delta>0$ ) pollution will remain too high. With the improvement of green attitude the deviation declines. The resulting development of the pollution time path is shown in figure 5 .

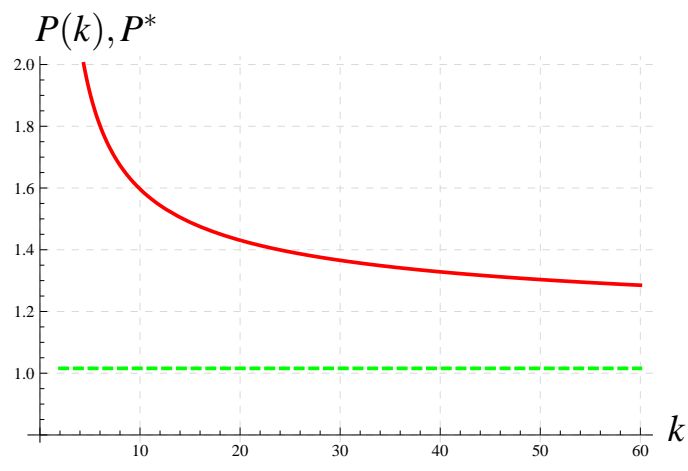

(a) small impact of wealth: $\xi_{k}=-0.2$

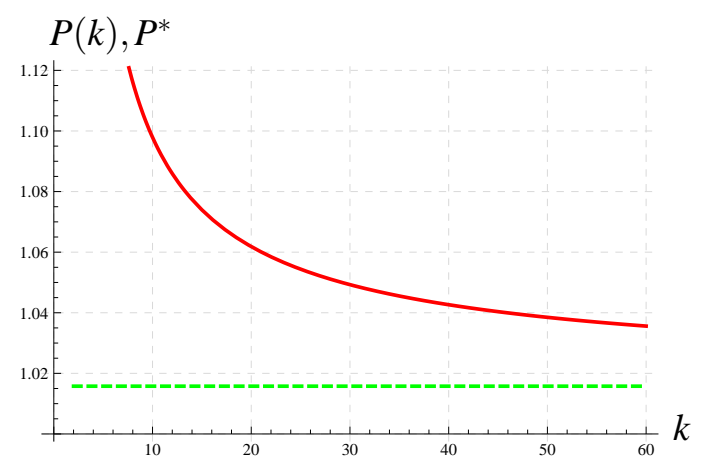

(b) large impact of wealth: $\xi_{k}=-0.7$

Figure 5: Transitional dynamics: adaption of environmental pollution; solid red line: $P(\delta(k))$ from (22), dashed green line: $P^{*}$ from (19); parameters: $\varepsilon=0.05, \rho=0.05, A=1.5, \gamma=2$

On the one hand, capital growth directly increases pollution. On the other hand it leads to an increase in expenditure for environmental protection. Pollution decreases because abatement activity grows faster than capital. As can be seen in equation (20) growth of abatement activity differs by the term $\widehat{(1-\delta)}>0$ from capital growth. Due to the change in green preferences, the growth rate of abatement expenditure exceeds the growth rate of capital in all time increments, hence pollution diminishes monotonically.

Given ongoing growth of capital, environmental awareness enhances $\left(\delta_{k}<0\right)$ and the perception parameter finally converges towards zero, $\lim _{t \rightarrow \infty} \delta(k)=0$. As a consequence, all individuals finally consider the entire impact of their decisions on environmental quality and all equilibrium values of consumption, pollution and growth converge to their respective optimal values

$$
\begin{aligned}
& \lim _{t \rightarrow \infty} \hat{k}=\frac{\varepsilon(A-(1+\gamma) \rho)}{1+(1-\varepsilon) \gamma}=\hat{k}^{*} \\
& \lim _{t \rightarrow \infty} P=\frac{1+(1-\varepsilon) \gamma}{\gamma(\varepsilon \rho+(1-\varepsilon) A)}=P^{*}
\end{aligned}
$$

The resulting level of environmental pollution will thus in the long run fall short of the equilibrium values presented in the last section with exogenous and constant environmental perception. The underlying reason for the convergence to the optimal values is that throughout the growth process knowledge and understanding for the relationships between capital accumulation, environmental protection and environmental quality increases. Of course we have to admit that the convergence towards the optimal growth 
path is due to the assumption that individual responsibility for the environment eventually will become perfect, hence the negative environmental externality disappears completely. However, in a more realistic setting the externality will only diminish and not disappear entirely. Thus capital growth and pollution level will approximate their optimal levels but the deviation will persist.

To summarize the results derived so far: The economy converges against the sustainable growth path if increased wealth enhances individual attitude towards the environment. The pollution level remains suboptimally high in the transition process and diminishes until green attitude becomes complete and the negative externality vanishes entirely. Capital growth may be either suboptimally low or suboptimally high in transition depending on whether the impact of wealth on green attitude is sufficiently strong.

\subsection{Green attitude determined by pollution}

In this part we analyse the impact of pollution on green attitude. We focus on the argument that an increase in the pollution level makes the consequences of economic decisions on environmental quality more obvious and hence improves green attitude. As regards the perception function, $\delta(P)$, we assume that $\delta_{P}<0$ and $\delta_{P P}>0$, where $\delta\left(P_{0}\right)<1$ and $\lim _{P \rightarrow \infty} \delta=0$ (compare Figure 3(b)). Additionally, at first we abstract from any impact of wealth on green attitude, that is $\delta_{k}=\xi_{k}=0$.

Pollution then evolves according to

$$
\hat{P}=\hat{k}-\hat{e}=\hat{k}-(\widehat{1-\delta(P}))-\hat{c}=\frac{\delta}{1-\delta} \xi_{P} \hat{P}-\widehat{c / k} \quad \Rightarrow \quad \hat{P}=-\frac{\widehat{c / k}}{1-\frac{\delta}{1-\delta} \xi_{P}}
$$

Consumption and capital will again grow with the same rate for a utility maximizing time path as derived in the appendix. Nevertheless, there is a change of the results as regards the evolution of abatement activity which now also evolves according to this growth rate. From (25) it is straightforward that the pollution level will be constant if consumption and capital grow with the same rate. Hence, within the dynamic equilibrium $\hat{c}=\hat{k}=\hat{e}$ holds at each point of time. Consequently the economy at once reaches the steady state growth path without the necessity to pass through a transition process. The growth equilibrium is then determined by the constant growth rate and a constant level of environmental pollution

$$
\begin{aligned}
& \hat{k}(\delta(P))=\frac{\varepsilon(A-(1+\gamma(1-\delta)) \rho)}{1+(1-\varepsilon) \gamma(1-\delta)} \\
& P(\delta(P))=\frac{1+(1-\varepsilon) \gamma(1-\delta)}{\gamma(1-\delta)(\varepsilon \rho+(1-\varepsilon) A)} .
\end{aligned}
$$


Equations (26) and (27) suggest that $\delta(P)$ can be determined uniquely in equilibrium. The pollution level depends on green attitude $(P=P(\delta))$ and green attitude depends on pollution $(\delta=\delta(P))$. Since pollution is increasing in the perception parameter, $\partial P / \partial \delta>0$, and the perception parameter is assumed to depend negatively on the pollution level, $\partial \delta / \partial P<0$, there is a unique and positive solution for equilibrium attitude towards the environment. Both functions are shown in Figure 6. The equilibrium perception level is reached instantaneously. Nevertheless one can imagine an adjustment towards the equilibrium. If the economy starts with less green attitude (higher $\delta$ ), individuals will take only a smaller part of influence on the environment into account. The according pollution level will be higher, thus individuals will recognize their impact on the environment and green attitude is enhanced (decreasing $\delta$ ).

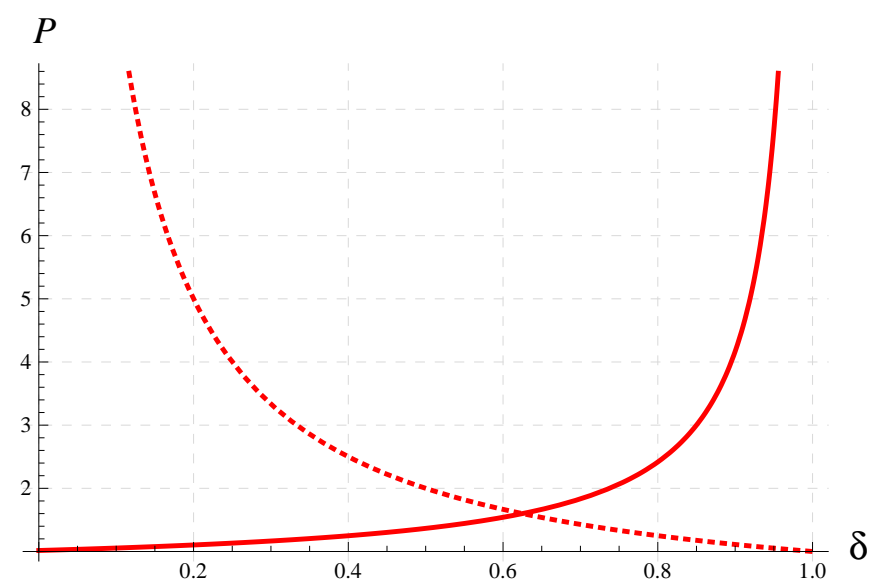

Figure 6: Equilibrium attitude towards the environment; parameters $\varepsilon=0.05, \rho=0.05, A=1.5, \gamma=2, \xi_{P}=$ -1 ; solid line $P(\delta)$ from (27), dashed line $\delta(P)$ as assumed

The resulting equilibrium level of pollution will be the lower (and equilibrium green attitude the more pronounced), the stronger environmental preferences (higher $\gamma$ ), the higher the rate of time preference $\rho$ or the higher capital productivity $A$. Stronger environmental preferences imply that dis-utility out of pollution gains importance, hence individuals give more weight on the environmental implications of their actions and behave more environmentally friendly. An increase in the rate of time preference, $\rho$, will decrease capital growth. Therefore equilibrium pollution decreases and equilibrium $\delta$ increases. An rise in productivity, $A$, will increase both capital growth and abatement activity. Equation (A.5) together with (10) show that the abatement ratio $e / k$ is increasing in capital productivity. The income effect of increasing productivity on abatement activity dominates the growth increasing impact. Thus the equilibrium level of pollution decreases. 
As already mentioned, the endogenous evolution of green attitude does not end up in the optimal growth path if perception is linked exclusively to environmental quality. In equilibrium, capital and environmental spending grow at identical rates. Then the pollution level remains unchanged without inducing any further impulses as regards perception. The economy remains at a suboptimal level and a transition to a sustainable growth path, as derived in the last section where increasing wealth is accompanied by a more sensitive environmental perception, may not be derived.

With the underlying simple assumptions the economy will immediately realize the steady state values of growth and pollution as indicated in (26) and (27). Of course, one can imagine that in reality green attitude will not adjust immediately. Instead, there will be a process of strengthening attitude towards the environment. A process where green attitude reacts on the previous level of pollution and pollution in turn results from the current environmental awareness could induce a cyclical adjustment process which would take time. Nevertheless, such phenomena cannot be analysed with the current version of the model, hence we let them for future research.

\subsection{Green attitude determined jointly by wealth and environment}

Finally we come back to the general assumption that green attitude is determined by wealth and by pollution simultaneously, hence $\delta=\delta(k, P)$ with the assumptions concerning the derivatives imposed above, see (2). Utility maximization again requires equal growth rates of consumption and capital, thus the consumption ratio $c / k$ remains constant. Growth rate and pollution level result as already derived in section 3

$$
\begin{aligned}
& \hat{k}(\delta(k, P))=\frac{\varepsilon(A-(1+\gamma(1-\delta)) \rho)}{1+(1-\varepsilon) \gamma\left(1-\delta-\frac{\delta \xi_{k}(1+\gamma(1-\delta))}{1-\delta-\delta \xi_{P}}\right)} \\
& P(\delta(k, P))=\frac{1+(1-\varepsilon) \gamma\left(1-\delta-\frac{\delta \xi_{k}(1+\gamma(1-\delta))}{1-\delta-\delta \xi_{P}}\right)}{(1+\gamma(1-\delta))\left(\varepsilon \rho+(1-\varepsilon)\left(1-\frac{\gamma \delta \xi_{k}}{1-\delta-\delta \xi_{P}}\right) A\right)}
\end{aligned}
$$

The effective intertemporal elasticity of substitution again is reduced by the impact of wealth on green attitude, $\xi_{k}$, as explained in section 4.1. More interestingly, the impact of pollution on green attitude now affects equilibrium growth. The impact of pollution on

green attitude, $\xi_{P}$, has both a direct and an indirect effect on capital growth. The direct impact is growth decreasing: the absolute value of the fraction in the denominator of (28) decreases, thus the denominator increases and capital growth decreases. The economic intuition of this direct effect is the following. As wealth increases and environmental education is extended, individuals are more aware of environmental concerns and reduce 
the pollution level. Due to increasing environmental quality, the necessity to behave environmentally friendly is less obvious and c. p. individuals care less about the environment. Capital accumulation increases. But additionally there is an indirect effect of the impact of pollution on green attitude: the perception parameter $\delta$ also is influenced by pollution. Whether green attitude enhances slower or faster during the transition process depends on the parameter setting. Consequently the overall effect on capital growth is ambiguous as shown in figure 7.

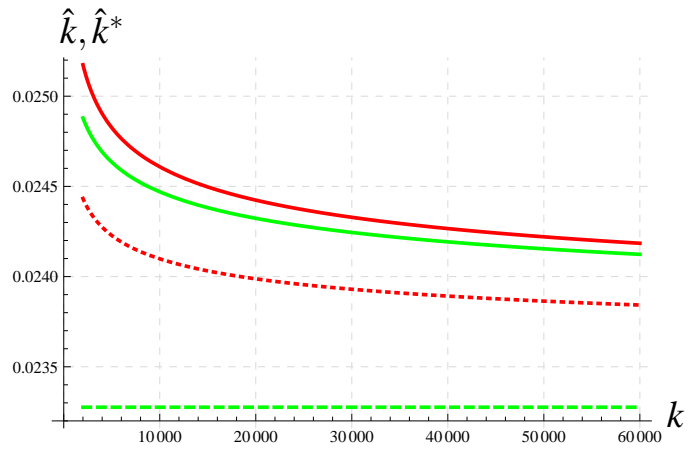

(a) small impact of wealth: $\xi_{k}=-0.2$

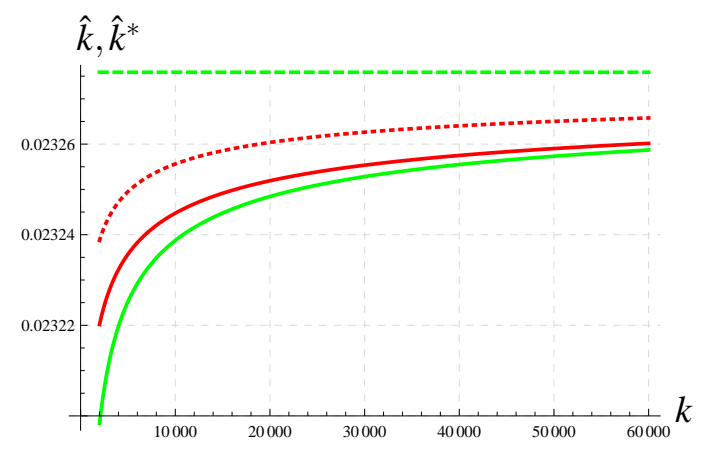

(b) large impact of wealth: $\xi_{k}=-0.4$

Figure 7: Capital growth in transition; solid red line: $\hat{k}(\delta(k, P))$ from (28) with low pollution $P=1.01$, dashed red line: $\hat{k}(\delta(k, P))$ from (28) with high pollution $P=2.5$, solid green line $\hat{k}(\delta(k))$ from (21), dashed green line $\hat{k}^{*}$ from (18); parameters: $\varepsilon=0.05, \rho=0.05, A=1.5, \gamma=2, \xi_{P}=-0.5$

Figure 7(a) shows that capital growth indeed may increase or decrease due to the additional impact of pollution on green attitude (red lines) compared with the case that green attitude is solely driven by wealth (solid green line). The effect predominantly depends on the current level of pollution. If pollution is high and individuals react on the level of pollution, green attitude enhances and capital growth decreases (dashed red line). This is what happened after the Fukushima nuclear accident. Pollution was high and individuals were disposed to change their attitude towards the environment. Hence behaviour became more environmentally friendly.

If instead pollution is low and individuals' green attitude reacts on environmental quality, they get convinced that environmental issues are unproblematic. Environmentally friendly behaviour becomes less important and capital growth (solid red line) exceeds the growth rate of an economy where only wealth determines green attitude. This is the approach of various elderly men in my circle of acquaintances. Since pollution has been reduced significantly in the last decades they claim not to take environmental concern too serious within economic decisions. 
Figure 7(b) captures the more unrealistic case that capital growth is suboptimally low because the impact of wealth on green attitude is sufficiently large. We already explained in section 4.1 that the ongoing decrease in effective capital return may lead to suboptimally low capital accumulation. In this case capital growth increases unambiguously due to the additional impact of pollution on green attitude, independent from the level of pollution. Within the transition process environmental quality increases thus reducing the obvious necessity for environmentally friendly behaviour.

Of course, the system of capital growth, pollution and green attitude is interdependent. There is not only the described impact of pollution on capital growth, but also an impact of capital accumulation on the pollution level. Pollution as given by (29) depends on green attitude, $\delta$, and green attitude is influenced by the capital stock. Thus in all time increments the resulting pollution level (c. p.) is lower the higher the capital endowment due to the improvement of green attitude.



Figure 8: Equilibrium attitude towards the environment; parameters $\varepsilon=0.05, \rho=0.05, A=1.5, \gamma=2, \xi_{k}=$ $-0.2, \xi_{P}=-0.5$; solid red line $P(\delta)$ from (29), dashed red line $\delta(k, P)$ from (2) with low $k(k=10)$, dashed green line $\delta(k, P)$ from (2) with high $k(k=100)$

The effect of capital endowment on the equilibrium pollution level is unequivocally negative, as displayed in figure 8 . An increase in wealth enhances green attitude ( $\delta$ decreases) which results in the shift of the function $\delta(k, P)$ to the left. Hence individuals give more weight on the environmental impact of their activities and reduce the equilbrium pollution level. The intersection point in figure 8 shifts downwards.

To conclude, the pollution level is decreased by capital accumulation since wealth influences green attitude positively. Nevertheless, the growth rate of capital may increase or decrease due to the impact of pollution on green attitude depending predominantly on 
the level of pollution. As demonstrated in figure 7(a), a high (low) pollution level will foster (hamper) green attitude because individuals are more (less) likely to understand the environmental consequences of their economic decisions. Thus capital growth decreases (increases). However slower (faster) capital growth means that environmental education increases slower (faster). This induces an opposed effect on green attitude: it will enhance slower (faster). The overall impact on the speed of convergence depends on the concrete parameter setting.

Anyway, due to ongoing capital growth, green attitude will improve until the perception parameter vanishes, that is $\lim _{t \rightarrow \infty} \delta=0$. Hence, capital growth converges to the socially optimal growth rate given in (23), as in the case $\xi_{k}<0, \xi_{P}=0$ where green attitude is determined exclusively by wealth. Whether convergence towards the social optimum is promoted or hindered depends on the parameter setting.

\section{Conclusion}

This paper focuses on the interdependency between green attitude, environmental quality and economic growth. We understand environmental externalities to be based on the incomplete perception of individual influences on environmental quality. Hence the determinants of this individual attitude towards the environment are centred, we focus on the impact of wealth and of pollution on green attitude. Wealth enhances green attitude because increasing wealth enables environmental education and eases green consumption. Pollution has a positive impact on green attitude because with higher pollution the environmental consequences of economic decisions become more obvious. We show that economic growth as well as the level of environmental quality are crucially influenced by the green attitude as well as by the evolution of green attitude.

Considering the impact of wealth on green attitude we show that both equilibrium growth rate and equilibrium environmental quality are subject to transitional dynamics. Capital growth is decreased due to the impact of wealth on green attitude. Within the growth process wealth increases, allows for more environmental education and improves green attitude. Hence, individuals are more aware of the consequences of their economic decisions on environmental quality and behave more environmentally friendly. Capital accumulation is decreased and pollution also decreases. Eventually, as a consequence of sufficiently high wealth, the individual's impact on environmental quality is completely included at the individual optimization calculus. Dynamic market equilibrium converges to the sustainable growth path.

The sensitivity of dynamics is highlighted by considering that environmental perception is not affected by individual wealth but is determined by environmental quality itself. 
For low pollution levels, individuals do not care about the impact of their activity on the environment. As environmental quality gets worse, we assume a higher sensitivity about the relationship between individual activity and aggregate pollution. However, given these assumptions, the aforementioned result of a transition to the sustainable growth path may not be retained. Instead, the resulting equilibrium is characterized by a constant level of environmental quality which still is suboptimally low. Due to the impact of pollution on the individual attitude towards the environment, environmental quality is increased. Nevertheless equilibrium environmental quality remains constant and will not improve over time.

If both wealth and pollution jointly determine green attitude, the dynamics of capital growth and environmental quality influence mutually. A larger wealth endowment uniquely decreases the resulting pollution level due to the associated improvement of green attitude. A higher pollution level has an ambiguous impact on capital growth depending predominantly on the level of pollution. In case of high pollution individuals learn about the relation between their economic decisions and the resulting environmental quality. Green attitude enhances and pollution as well as capital growth decrease. In case of low pollution the improvement of green attitude is hampered resulting in an increase in capital growth. Whether convergence to the optimal growth path is accelerated or decelerated depends on the specific parameter setting.

\section{Appendix: derivation of transitional dynamics}

Transition to the long-run equilibrium is determined by the evolution of the consumption ratio, $c / k$, the pollution level, $P$, and the growth rate of capital, $\hat{k}$. Inserting (13) within (12) and solving for $\hat{P}$ yields

$$
\hat{P}=\frac{1}{1-\frac{\delta}{1-\delta} \xi_{P}}\left(\frac{\delta}{1-\delta} \xi_{k} \hat{k}-\widehat{c / k}\right)
$$

One can see that the attitude towards the environment will centrally influence the development of pollution.

The equilibrium evolution of the consumption ratio $\widehat{c / k}=\hat{c}-\hat{k}$ can be calculated from the growth rate of consumption (11) and capital accumulation

$$
\hat{k}=A-\frac{c}{k}-\frac{e}{k}=A-(1+\gamma(1-\delta)) \frac{c}{k}
$$

such that economic and environmental development are uniquely determined. Using $\hat{P}$ from (A.1) and the consumption growth rate (11) in $\widehat{c / k}$ results in

$$
\widehat{c / k}=\varepsilon\left(A-\gamma(1-\delta) \frac{c}{k}-\rho-\gamma\left(1-\frac{1}{\varepsilon}\right)\left(\xi_{k} \frac{\delta}{1-\delta} \hat{k}-\widehat{c / k}\right)\right)-\hat{k}
$$


Inserting (A.2) and solving for the growth rate of the consumption ratio yields

$$
\begin{aligned}
\underbrace{\left(1+\frac{(1-\varepsilon) \gamma(1-\delta)}{1-\delta-\delta \xi_{P}}\right)}_{>0} \widehat{c / k}= & -\left(\varepsilon \rho+(1-\varepsilon)\left(1-\frac{\gamma \delta \xi_{k}}{1-\delta-\delta \xi_{P}}\right) A\right) \\
& +\left(1+\gamma(1-\varepsilon)\left(1-\delta-\frac{\delta \xi_{k}(1+\gamma(1-\delta))}{\left.1-\delta-\delta \xi_{P}\right)}\right)\right) \frac{c}{k}
\end{aligned}
$$

which leads to the evolution of the consumption ratio as given by

$$
\widehat{c / k} \gtrless 0 \quad \Longleftrightarrow \quad \frac{c}{k} \gtrless \frac{\varepsilon \rho+(1-\varepsilon)\left(1-\frac{\gamma \delta \xi_{k}}{1-\delta-\delta \xi_{P}}\right) A}{1+\gamma(1-\varepsilon)\left(1-\delta-\frac{\delta \xi_{k}(1+\gamma(1-\delta))}{\left.1-\delta-\delta \xi_{P}\right)}\right)} \equiv \mu
$$

It is straightforward that the consumption ratio is unstable such that intertemporal utility maximization implies the choice of the consumption ratio $c / k=\mu$. As a consequence, throughout the equilibrium transition process growth of both capital and consumption coincide. The growth rate of capital results as follows

$$
\hat{k}=A-(1+\gamma(1-\delta)) \mu=\frac{\varepsilon(A-(1+\gamma(1-\delta)) \rho)}{1+(1-\varepsilon) \gamma\left(1-\delta-\frac{\delta \xi_{k}(1+\gamma(1-\delta))}{1-\delta-\delta \xi_{P}}\right)}
$$

\section{References}

Brock, W. and Taylor, M. S.: 2005, Economic growth and the environment, in P. Aghion and S. Durlauf (eds), Handbook of Economic Growth, Vol. 1, Elsevier, North Holland, pp. 1749-1821.

Edwards, J. H. Y.: 1990, Congestion function specification and the 'publicness' of local public goods, Journal of Urban Economics 27, 80-96.

Eicher, T. and Turnovsky, S.: 2000, Scale, congestion and growth, Economica 67, 325-346.

Epstein, L. G. and Zin, S. E.: 1989, Substitution, risk aversion, and the temporal behaviour of consumption and asset returns: A theoretical framework, Econometrica 57, 937-969.

Eriksson, C.: 2004, Can green consumerism replace environmental regulation? a differentiated-products example, Resource and Energy Economics 26, 281-293.

European Commission: 2008, Eurobarometer Spezial - Attitudes of European citizens towards the environment, Bericht 295, Europäische Kommission, Brüssel.

URL: www. socioilogico.com/Attitudes_Europeans_MD_2007. pdf

European Commission: 2011, Eurobarometer Spezial - Attitudes of European citizens towards the environment, Bericht 365, Europäische Kommission, Brüssel.

URL: www. socioilogico. com/Attitudes_Europeans_MD_2007. pdf 
Fisher, W. H. and Turnovsky, S. J.: 1998, Public investment, congestion, and private capital accumulation, The Economic Journal 108, 399-413.

Glaeser, E. L.: 2005, The supply of environmentalism: Psychological interventions and economics, Review of Environmental Economics and Policy 8(2), 208-229.

Glomm, G. and Ravikumar, B.: 1994, Public investment in infrastructure in a simple growth model, Journal of Economic Dynamics and Control 18, 1173-1187.

Gradus, R. and Smulders, S.: 1993, The trade-off between environmental care and longterm growth - pollution in three prototype growth models, Journal of Economics 58, 2551 .

Grimaud, A.: 1999, Pollution permits and sustainable growth in a Schumpeterian model, Journal of Environmental Economics and Management 38, 249-266.

Grimaud, A. and Tournemaine, F.: 2007, Why can environmental policy tax promote growth through the channel of education?, Ecological Economics 62, 27-37.

Hall, R. E.: 1988, Intertemporal substitution in consumption, Journal of Polictical Economy 96(2), 339-357.

Ono, T.: 2002, The effects of emission permits on growth and the environment, Environmental and Resource Economics 21, 75-87.

Pautrel, X.: 2012, Environmental policy, education and growth: A reappraisal when lifetime is finite, Macroeconomic Dynamics 16, 661-685.

Ramsey, F. P.: 1928, A mathematical theory of saving, The Economic Journal 38, 239-263.

Schumacher, I.: 2009, The dynamics of environmentalism and the environment, Ecological Economics 68, 2842-2849.

Schumacher, I. and Zou, B.: 2008, Pollution perception: A challenge for intergenerational equity, Journal of Environmental Economics and Management 55, 296-309.

Smulders, S. and Gradus, R.: 1996, Pollution abatement and long-term growth, European Journal of Political Economy 12, 505-532.

Stokey, N. L.: 1998, Are there limits to growth?, International Economic Review 39, 1-31.

Turnovsky, S. J.: 2000, Methods of Macroeconomic Dynamics, 2 edn, MIT Press, Cambridge/Mass.

Xepapadeas, A.: 2005, Technological opportunities and industrial organisation, in K.-G. Mäler and J. Vincent (eds), Handbook of Environmental Economics, Vol. 3, Elsevier, North Holland. 


\section{Working Paper Series in Economics}

recent issues

No. 68 Ingrid Ott and Susanne Soretz: Green attitude and economic growth, May 2015

No. 67 Nikolaus Schweizer and Nora Szech: Revenues and welfare in auctions with information release, April 2015

No. 66 Andranik Tangian: Decision making in politics and economics: 6. Empirically constructing the German political spectrum, April 2015

No. 65 Daniel Hoang and Martin Ruckes: The effects of disclosure policy on risk management incentives and market entry, November 2014

No. 64 Sebastian Gatzer, Daniel Hoang, Martin Ruckes: Internal capital markets and diversified firms: Theory and practice, November 2014

No. 63 Andrea Hammer: Innovation of knowledge intensive service firms in urban areas, October 2014

No. 62 Markus Höchstötter and Mher Safarian: Stochastic technical analysis for decision making on the financial market, October 2014

No. 61 Kay Mitusch, Gernot Liedtke, Laurent Guihery, David Bälz: The structure of freight flows in Europe and its implications for EU railway freight policy, September 2014

No. 60 Christian Feige, Karl-Martin Ehrhart, Jan Krämer: Voting on contributions to a threshold public goods game - an experimental investigation, August 2014

No. 59 Tim Deeken and Ingrid Ott: Integration as a spatial institution: Implications for agglomeration and growth, July 2014

No. 58 Mher Safarian: Erhaltungsgesetze für das Modell $M_{r}\left|G_{r}\right| 1 \mid \infty$ in der Klasse der konservativen Abfertigungsdisziplinen, July 2014 